\title{
A PROTEÇÃO DE DADOS DO CONSUMIDOR NO COMÉRCIO ELETRÔNICO (E-COMMERCE): ANÁLISES DA LEI N. 13.709/2018 NAS RELAÇÕES DE CONSUMO VIRTUAIS
}

\author{
THE PROTECTION OF CONSUMER INFORMATION IN E-COMMERCE ANALYSIS OF LAW \\ NO. 13.709/2018 IN VIRTUAL CONSUMER RELATIONS
}

\section{Laryssa Carolyne Oliveira Pinto}

Universidade Federal de Roraima, Boa Vista, RR, Brasil. E-mail: laryakarolyni@gmail.com

\section{Douglas Verbicaro Soares}

Universidade Federal de Roraima, Boa Vista, RR, Brasil. E-mail: douglas_verbicaro@yahoo.com.br

DOI: https://doi.org/10.46550/ilustracao.v2i3.68

Recebido em: 21.06.2021

Aceito em: 04.09.2021

\begin{abstract}
Resumo: $\mathrm{O}$ presente artigo traz como tema a proteção de dados do consumidor no comércio eletrônico, com enfoque na análise da Lei Geral de Proteção de Dados Pessoais - LGPD. Nas últimas duas décadas, houve um crescente avanço na utilizaçấo da internet para se realizar compras e contratar serviços. Consequente-mente, tornou-se um desafio para os juristas a possibilidade de acompanhamento das atualizaçôes acerca da nova relação de consumo. Tal fato se tornou ainda mais difícil quando surgiu o novo modo de contratar - o contrato eletrônico. A referida prática não apenas trouxe muitos benefícios para a populaçáo brasileira e, ainda, para o mundo, como também trouxe riscos, notadamente aqueles que envolvem a segurança da informação nos dados do consumidor. Para tanto, neste trabalho foram utilizadas as metodologias de pes-quisa bibliográfica, exploratória e qualitativa.
\end{abstract}

Palavras-chave: Tecnologia. Consumidor. Decreto n. 7.962/2013. Lei n. 13.709/2018.

\begin{abstract}
This article focuses on the protection of consumer data in e-commerce, focusing on the analysis of the General Law on the Protection of Personal Data - LGPD. In the last two decades, there has been a grow-ing advance in the use of the Internet to make purchases and hire services. Consequently, it has become a challenge for legal experts to monitor updates on the new consumer relationship. This fact became even more difficult when the new way of hiring emerged - the electronic contract. This practice not only brought many benefits to the Brazilian population and, also to the world, but also brought risks, especially those that involve information security in consumer data. For this, this work used the methodologies of bibliographic, exploratory, and qualitative research.
\end{abstract}

Keywords: Technology. consumer. Decree No. 7.962/2013. Law no. 13.709/2018. 


\section{Introdução}

Esta pesquisa aborda sobre a proteção de dados do consumidor no comércio eletrônico, a fim de se verificar a inferência da Lei Geral de Proteção de Dados Pessoais e os limites de sua aplicabilidade no tratamento de dados pessoais.

A justificativa desta análise é viável para a discussão social sobre o tema, uma vez que a internet é uma ferramenta que, nas últimas duas décadas, tornou-se cada vez mais presente na vida das pessoas em sociedade. Consequentemente, o uso do ambiente virtual passou a ser corriqueiro para, praticamente, todo e qualquer assunto que envolvesse a vida de uma pessoa (notadamente) para a realização de compras virtuais.

Nesse contexto, surgiu um novo modo de contratar no âmbito das relaçóes de consumo, que eram celebradas, até então, apenas por contratos físicos e, após o surgimento de sites de compras, passaram a ser celebrados por meio de contratos virtuais, ensejando, assim, na figura do contrato eletrônico.

Esse novo modo de contratar foi visto com uma revolução no âmbito do direito do consumidor, trazendo consigo uma série de peculiaridades que o destacou das demais espécies contratuais. Consequentemente, os juristas se viram na obrigação de fazer um acompanhamento nas mudanças que iam se estabelecendo no ambiente da relação de consumo.

Não obstante, mister destacar a premissa de que "os fatos atropelam a lei", tanto pelo rápido desenvolvimento tecnológico, quanto pela rapidez com que se estabelecem novas relaçóes sociais ou jurídicas.

Com base nessa realidade, surgiram normas regulamentadoras para o uso de dados na internet, destacando a lei n. 12.965/2014, que dispóe sobre o Marco Civil da Internet. Entretanto, as leis que surgiram, nos últimos anos, careciam de um fator importante que se tornou crucial para que se estabelecesse um debato no âmbito do Ordenamento Jurídico brasileiro: o tratamento de dados pessoais no ambiente virtual.

A necessidade de se discutir a regulamentação para o tratamento de dados pessoais em território brasileiro restou indispensável, uma vez que constatado na legislação esparsa que as normas vigentes não estavam em conformidade com o Regulamento Geral de Proteção de Dados Pessoais Europeu n. 679, aprovado em 27 de abril de 2016 (GDRP).

Desta forma, viu-se a necessidade de adequação do Ordenamento Jurídico brasileiro face ao restante do mundo, uma vez que as relaçóes comerciais aqui estabelecidas transpassariam o território brasileiro, estabelecendo-se relaçóes de consumo nos mais diversos países integrantes da UE (União Europeia).

A partir dessa realidade se deu início à discussão e posterior aprovação da Lei n. 13.709/2018 (LGPD), que trouxe consigo princípios e regramentos acerca do tratamento de dados pessoais no ambiente virtual. Sendo, assim, o presente estudo tem como principal objetivo examinar a figura do consumidor inserida no ambiente do e-commerce, destacando-se a sua hipervulnerabilidade face à celebração de contratos virtuais. Bem como o comportamento da 
Lei n. 13.709/2018 no ambiente de consumo virtual, explicitando-se sua aplicaçáo quanto ao tratamento de dados pessoais do consumidor.

Esta lei se destaca das demais, pois traz em seu bojo conceitos, princípios, fundamentos e regras que norteiam a política de tratamento de dados, tanto no setor público quanto no setor privado, sugerindo-se, por fim, a implantação de uma política de segurança de informação baseada na própria relação de consumo.

A lei protecionista é evidenciada nesta pesquisa de forma a demonstrar sua importância na regulamentação quanto à segurança no tratamento de dados pessoais, notadamente, naqueles que estão inseridos no banco de dados e cadastros de consumo. Portanto, a presente investigação torna-se crucial para o entendimento acerca da aplicabilidade da referida lei, que traz em seu arcabouço normativo mecanismos importantes que proporcionam ao consumidor a segurança, transparência e qualidade no tratamento de seus dados pessoais.

Para a estrutura do estudo, se optou por levantamento bibliográfico e documental, com abordagem qualitativa em um método dedutivo. A investigação apresenta duas seçôes: A primeira versa sobre o conceito de consumidor e a ideia de hipervulnerabilidade na contratação virtual. A segunda seção aborda a Lei Geral de Proteção dos Dados Pessoais e nuances do Código de Defesa do Consumidor.

\section{Consumidor: A hipervulnerabilidade na contratação eletrônica}

Historicamente, o consumidor sempre foi apontado como o pólo mais vulnerável da relação contratual, pois, nas palavras do ex-presidente John Kennedy, em seu discurso feito ao Congresso Americano, em 15 de março de 1962:

Consumidores, por definição, somos todos nós. Eles são o maior grupo no cenário econômico, afetando e sendo afetados por quase todas as decisóes econômicas, sejam elas públicas ou privadas. Dois terços de todos os gastos na economia advêm dos consumidores. Mas eles são o único grupo importante na economia que não são efetivamente organizados, cujos pontos de vista muitas vezes não são ouvidos (JONH F. KENNEDY PRESIDENTIAL LIBRARY E MUSEUM, 1962).

Dessa forma, o Código de Defesa do Consumidor (BRASIL, 1990), ao ser elaborado, teve como principal arcabouço principiológico a Constituição Federal de 1988 (BRASIL, 1988), e muito do que se vê no referido diploma legal tem base na Lei Maior.

É importante ressaltar que os princípios elencados no CDC, notadamente, o princípio da vulnerabilidade do consumidor, previsto no art. 4º I, do CDC (BRASIL, 1990), guarda relação tênue com o art. 5, inc. XXXII, da CF/88, que diz o seguinte: $\mathrm{O}$ Estado promoverá na forma da lei, a defesa do consumidor (BRASIL, 1988).

Denota-se do referido mandamento constitucional a clara intenção do constituinte, ao reconhecer o consumidor como a parte mais vulnerável da relação, a ponto de incumbir a obrigação ao Estado para a guarda e proteção do consumidor. Neste sentido, a presente pesquisa buscou analisar, sob o aspecto doutrinário e legal, a mais recente modalidade de contratação: a contratação eletrônica, bem como seus aspectos positivos e negativos, como também, os diferentes graus de vulnerabilidade a que o consumidor está sujeito.

Ainda, analisar-se-á, a Lei n. 13.709/2018 e sua implicação na proteção dos dados do consumidor, importante ferramenta de combate às práticas abusivas cometidas pelas empresas, 
notadamente quanto ao tratamento de dados desse consumidor no comércio eletrônico.

\subsection{Conceito de consumidor}

O CDC estabelece, em seu art. $2^{\circ}$, que consumidor é toda pessoa física ou jurídica que adquire ou utiliza produto ou serviço como destinatário final (BRASIL, 1990).

Não obstante, a doutrina aponta que são 03 (três) os elementos a comporem o conceito de consumidor, quais sejam: o subjetivo (pessoa física ou jurídica), o objetivo (aquisição ou utilização de produtos ou serviços), e o teleológico (a finalidade pretendida com a aquisição do produto ou serviço) que, por sua vez, é caracterizado pela expressão "destinatário final" (NERY JÚNIOR, 2000, p. 430).

Contudo, é possível vislumbrar outras definiçóes de consumidor em vários artigos do CDC (BRASIL, 1990), com destaque a discussão doutrinária acerca do que seja destinatário final. Neste sentido, é possível diferenciar no âmbito da doutrina consumerista dois seguimentos, qual sejam: finalistas e maximalistas.

A doutrina finalista, nas palavras de Marques, ensina que destinatário final é o destinatário fático e econômico do bem ou serviço, seja ele pessoa jurídica ou física, ou seja, deve-se estar na posição de destinatário final econômico do bem (MARQUES, 2003, p. 53). De acordo com esse conceito, torna-se inviável o reconhecimento da pessoa jurídica como consumidora uma vez que os produtos ou serviços adquiridos são utilizados, ainda que indiretamente, na atividade lucrativa (GARCIA, 2017, p. 25).

Distingue-se, aí, a corrente maximalista, que se utiliza do conceito jurídico de consumidor, apontando que o destinatário final seria somente o destinatário fático, sendo irrelevante a destinação econômica do bem a ser adquirido (GARCIA, 2017, p. 29).

$\mathrm{Na}$ contramão, Tartuce entende que, muito embora a questão da pessoa jurídica possa causar controvérsia, o consumidor, pode ser uma pessoa natural ou jurídica, náo havendo qualquer diferença para fins de enquadramento (TARTUCE, 2016, p. 74). Entretanto, não foi essa a posição a que o legislador se filiou.

O conceito legal ainda é objeto recorrente de discussóes no âmbito doutrinário, principalmente quando se fala do consumidor como sendo a pessoa jurídica, uma vez que o que se costuma ver, pela própria cultura nas relaçóes comerciais, é a pessoa jurídica como sendo o fornecedor do produto ou serviço e não contrário. Dessa forma, Marques traz à baila uma corrente que seria o "meio-termo" entre as duas anteriores, que denominamos de teoria finalista temperada, aprofundada ou mitigada.

Neste ínterim, destaca a doutrina que em casos difíceis envolvendo pequenas empresas que utilizam insumos para a sua produção, mas não em sua área de expertise ou com uma utilização mista, principalmente na área de serviços, provada a vulnerabilidade, conclui-se pela destinação final de consumo prevalente, ou seja, a palavra-chave, neste caso, é vulnerabilidade (MARQUES et al., 2010, p. 87). 
Portanto, encontra-se, nesta teoria, a mesclagem da teoria maximalista (teoria maximalista temperada, aprofundada ou mitigada) e a teoria finalista, conforme a lições da ilustre autora.

Nota-se, com base nas teorias acima apresentadas, que o conceito do que seja consumidor, para fins de aplicação do CDC, ainda é um conceito náo pacificado no campo doutrinário. Entretanto, a corrente que se melhor adéqua ao referido diploma legal é a Teoria finalista, a qual destaca que consumidor é aquele que adquire (utiliza) um produto para uso próprio ou de sua família, ou seja, para fins pessoais e não profissionais e/ou visando o lucro.

\subsection{Os tipos de consumidor e a vulnerabilidade de situação no comércio eletrônico}

Muito se fala em vulnerabilidade como sendo o elemento essencial e precípuo para se caracterizar uma relação de consumo.

Neste seguimento, Marques é enfática ao afirmar que seria necessário extrair do conceito legal de consumidor a sua interpretação teleológica, buscando, assim, o principal fundamento da norma (MARQUES, 2003). Desta forma, o destinatário final, para efeitos de definição do conceito de consumidor, seria somente aquele que, segundo o art. $4^{\mathrm{o}}$, fosse reconhecido como "vulnerável" numa relação, pois somente esses merecem a tutela especial do CDC (GARCIA, 2017, p. 31).

A vulnerabilidade, portanto, decorre da condição de que o consumidor está potencialmente sujeito a ser ofendido, seja no sentido físico, psíquico ou econômico do termo (DO CANTO, 2015, p. 66).

Assim, o referido princípio, que dá causa à existência do direito do consumidor, distingue-se, conforme assinala Marques, em três tipos de vulnerabilidades a serem destacadas: a técnica, a jurídica (ou científica) e a fática (ou socioeconômica). Tais espécies serão analisadas detalhadamente para que se possa compreender em que grau de vulnerabilidade o consumidor se encontra no âmbito do e-commerce.

\subsection{Vulnerabilidade técnica:}

De acordo com a autora, a vulnerabilidade técnica é determinada pela ausência de conhecimento especializado do consumidor em relação aos produtos e serviços que está contratando. Por não deter informações específicas, fica o consumidor subordinado aos caprichos daqueles que dominam determinada técnica ininteligível aos olhos de um leigo. Recai sobre o fornecedor, consequentemente, a presunção de que conhece as qualidades, as propriedades e os atributos essenciais dos produtos ou serviços que disponibiliza (MARQUES; MIRAGEM, 2012, p. 154-155).

Neste sentido, a referida autora destaca que o comprador não possui conhecimentos específicos sobre o objeto adquirido e, portanto, é mais facilmente enganado quanto às características do bem ou quanto à sua utilidade, [...]. A vulnerabilidade técnica, no sistema do CDC, é presumida para o consumidor não profissional, destinatário fático do bem, mas também pode atingir o profissional, destinatário final fático do bem (MARQUES et al., 2013, p. 99-102). 


\section{a) Vulnerabilidade Jurídica ou cientifica}

Este tipo de vulnerabilidade, conforme Paulo Valério Dal Pai Moraes, é notada tanto quando se forma a contenda judicial quanto numa fase pré-processual em que o consumidor desconhece os direitos e deveres que decorrem da relação de consumo [...] (MORAES, 2009, p. 147).

Neste sentido, Marques ensina que a vulnerabilidade jurídica ou científica é falta de conhecimentos jurídicos específicos, conhecimentos de contabilidade ou de economia. Esta vulnerabilidade, no sistema do Código de Defesa do Consumidor, é presumida para o consumidor não profissional e para o consumidor pessoa física (MARQUES, 2011, p. 324).

Entretanto, a autora destaca que, em relação aos profissionais e às pessoas jurídicas vale a presunção em contrário, ou seja, devem ter conhecimentos jurídicos mínimos e sobre economia para poderem exercer a profissão ou, ainda, consultar advogados e profissionais especializados antes tomarem alguma decisão (MARQUES et al., 2013, p. 99-102).

\section{b) Vulnerabilidade fática ou socioeconômica}

De acordo com Marques, a referida vulnerabilidade, em que o ponto de concentração é outro parceiro contratual, o fornecedor que, por sua posição de monopólio, fático ou jurídico, por seu grande poder econômico ou em razão da essencialidade do serviço, impóe sua superioridade a todos que com ele contratam (MARQUES, 2011, p. 330-331).

Assim, ensina Miragem, que a vulnerabilidade fática ou socioeconômica abrange diversas situaçôes concretas em que o consumidor será reconhecido como a parte mais fraca, sendo a mais comum a vulnerabilidade econômica (MIRAGEM, 2012, p. 101).

Importante destacar que a referida vulnerabilidade tem seu notório reconhecimento, decorrente de sua previsão legal, no art. 4, I do CDC, in verbis (BRASIL, 1990):

Art. 4o A Política Nacional das Relaçôes de Consumo tem por objetivo o atendimento das necessidades dos consumidores, o respeito à sua dignidade, saúde e segurança, a proteçáo de seus interesses econômicos, a melhoria da sua qualidade de vida, bem como a transparência e harmonia das relaçóes de consumo, atendidos os seguintes princípios: (Redação dada pela Lei no 9.008, de 21.3.1995)

I - Reconhecimento da vulnerabilidade do consumidor no mercado de consumo.

Não de outro modo, Blum reforça que é extremamente relevante o entendimento a respeito do princípio da vulnerabilidade porque, em situaçóes pouco claras sobre o consumidor/pessoa jurídica se enquadrar ou náo no conceito de consumidor (como se pode ver em diversos julgados de tribunais estaduais e até mesmo dos Tribunais superiores), se presente, a vulnerabilidade poderá contribuir para a incidência do CDC (BLUM, 2018, p. 58).

\section{c) Vulnerabilidade informacional ou informativa}

Nas liçôes de Marques e Miragem, a vulnerabilidade informacional, naturalmente, 
decorre do déficit de informaçóes do consumidor diante do fornecedor especialista. Contudo, os autores destacam que essa fraqueza não se confunde com a vulnerabilidade técnica, uma vez que hoje "a informação não falta, ela é abundante, manipulada, controlada e, quando fornecida, nos mais das vezes, desnecessária” (MARQUES; MIRAGEM, 2012, p.158).

Os autores, ainda, reforçam que a referida vulnerabilidade não deixa, porém, de representar, na nossa atualidade, o maior fator de desequilíbrio da relaçáo em face dos fornecedores, os quais, por sua vez, são os únicos verdadeiramente detentores da informação (MARQUES; MIRAGEM, 2012, p. 158).

Marques é pontual ao destacar como a vulnerabilidade do consumidor é evidenciada com o uso da internet, pois aquela aumenta em função da presença do meio eletrônico, e porque a capacidade de controle do indivíduo fica diminuída, pois é guiado por links e conexôes, assim como, também, o consumidor recebe as informaçôes que lhe desejam informar, de forma que há poucas possibilidades de identificar simulaçôes e de proteger a sua privacidade (MARQUES, 2004, p. 72).

Com base na análise acima referida é que foi proposto o PLS 281/2012, que deu origem ao Decreto n. 7.962/13 que, por sua vez, dispóe sobre a contratação no comércio eletrônico.

\section{d) Hipervulnerabilidade do consumidor:}

Ainda, Marques trouxe à baila um novo tipo de vulnerabilidade, mais notadamente, concentrada no campo da vulnerabilidade de situação, denominada de Hipervulnerabilidade do consumidor.

Fazendo um breve paralelo histórico, quanto à origem do conceito, a autora explica que o referido conceito foi desenvolvido pela primeira vez, no âmbito do território nacional, por Antonio Herman V. Benjamin, em 08.09.2005 (BENJAMIN, 2011, p. 445), na cidade de Gramado (RS), no Congresso Internacional "15 anos de CDC: balanço, efetividade e perspectivas", organizado pelo Brasilcon e pelas Escolas Superiores da Magistratura e do Ministério do Rio Grande do Sul (MARQUES; MIRAGEM, 2012, p.159).

Neste sentido, reforça-se que o grupo hipervulnerável de consumidores, neste inclusos as crianças, os idosos, os enfermos, as pessoas com necessidades especiais e os analfabetos, demanda uma maior proteção em virtude de determinadas características pessoais (NISHIYAMA, 2010, p. 13-45).

No tocante à hipervulnerabilidade da criança, a doutrina destaca que esta decorre de sua capacidade reduzida de julgamento e de sua inexperiência quanto aos aspectos práticos da contrataçáo e do funcionamento do mercado de consumo, de forma que a criança se torna um "alvo fácil" de mensagens publicitárias, devido à dificuldade de analisar de modo crítico as informaçôes trazidas pelos fornecedores, além de não saber distinguir quando a comunicação é feita exclusivamente para fins comerciais (DO CANTO, 2015, p. 70).

É tão notória a hipervulnerabilidade da criança no mercado de consumo que, em consequência disso, a Constituição Federal de 1988 instituiu o princípio geral da prioridade de proteção à criança, expressa em seu art. 227, in verbis (BRASIL, 1988):

Art. 227. É dever da família, da sociedade e do Estado assegurar à criança, ao 
adolescente e ao jovem, com absoluta prioridade, o direito à vida, à saúde, à alimentação, à educação, ao lazer, à profissionalização, à cultura, à dignidade, ao respeito, à liberdade e à convivência familiar e comunitária, além de colocálos a salvo de toda forma de negligência, discriminação, exploração, violência, crueldade e opressão (Redação dada Pela Emenda Constitucional no 65, de 2010).

De acordo com Do Canto, a Lei n. 8.078/1990 (BRASIL, 1990) vai além, ao estatuir, com base no referido princípio constitucional, em seu art. $37, \mathbb{\$} 2^{\circ}$, que toda a publicidade que se aproveite dessa condição de hipervulnerável do infante será considerada abusiva (DO CANTO, 2015, p. 71).

Ainda, o referido autor comenta que o art. 39, IV, do CDC, em complementação, prevê a proteção das crianças contra qualquer conduta negocial do fornecedor que prevalecer-se da fraqueza ou ignorância do consumidor, tendo em vista sua idade, saúde, conhecimento ou condição social, para impingir-lhe seus produtos ou serviços (DO CANTO, 2015, p. 71).

Neste sentido, o legislador agiu de forma coerente ao estabelecer no art. 39, IV, do CDC, a proteção da criança contra qualquer conduta do fornecedor que guarde a intenção de se prevalecer da fraqueza ou ignorância do consumidor, tendo em vista sua idade, saúde, conhecimento ou condição social, para impingir-lhe seus produtos ou serviços (BRASIL, 1990).

Da mesma forma, a Lei n. 8.069/90, prevê, de forma mais abrangente, em seu art. 17, tanto a proteção da criança, como também, a proteção do adolescente, no que diz respeito à integridade física, psíquica e moral (BRASIL, 1990).

Com base nos referidos diplomas, é possível notar o quanto o infante se torna um dos principais alvos no mercado consumerista, de tal forma que o objetivo dos referidos dispositivos traz como principal enfoque a proteção, não apenas de forma legal, mas também, no aspecto social. Uma vez que o dever de proteçáo à criança e ao adolescente é incumbido não apenas ao Estado, mas também a toda a sociedade, de uma forma geral, visando, assim, à maior efetividade na aplicação das normas consumeristas.

Outro grupo considerado hipervulnerável pela doutrina é aquele constituído pelos idosos. Miragem ensina que o alto nível de vulnerabilidade dos idosos se dá por dois principais fatores: a) a diminuição ou perda de determinadas aptidóes físicas e intelectuais que o torna mais suscetível e débil em relação a atuação negocial dos fornecedores; e b) necessidade e catividade em relação a determinados produtos ou serviços no mercado de consumo, que o coloca numa relaçáo de dependência em relação aos seus fornecedores (MIRAGEM, 2012, p. 104).

No que se refere à primeira característica, o autor afirma que essa se assemelha à hipervulnerabilidade infantil, uma vez que o fornecedor se aproveita da fraqueza ou ignorância do consumidor idoso para lhe impingir produtos ou serviços. Quanto à segunda característica, o autor ensina que ela está vinculada a maior dependência do consumidor-idoso a produtos e serviços específicos, presumindo-se que um eventual inadimplemento por parte do fornecedor dê causa a danos mais graves do que seriam de se indicar aos consumidores em geral (MIRAGEM, 2012, p. 104).

Diante disto, o constituinte, da mesma forma que se preocupou com a proteção da criança nas situaçóes acima citadas, também agiu de forma similar em relação ao idoso, ao estabelecer no art. 230 da Lei Maior que "A família, a sociedade e o Estado têm o dever de amparar as pessoas idosas, assegurando sua participação na comunidade, defendendo sua dignidade e bem-estar e 
garantindo-lhes o direito à vida" (BRASIL, 1988).

Neste sentido, a legislação consumerista não foi diferente, ao prever, no art. 39, IV, como vedação de uma de suas práticas abusivas do fornecedor a seguinte: prevalecer-se da fraqueza ou ignorância do consumidor, tendo em vista sua idade, saúde, conhecimento ou condição social, para impingir-lhe seus produtos ou serviços (BRASIL, 1990).

Ainda, o Estatuto do Idoso, seguindo os parâmetros constitucionais, prevê, em seus artigos 10 e 15, as seguintes disposiçóes, no que se refere à proteção do idoso no mercado de consumo (BRASIL, 2003):

Art. 10. É obrigação do Estado e da sociedade, assegurar à pessoa idosa a liberdade, o respeito e a dignidade, como pessoa humana e sujeito de direitos civis, políticos, individuais e sociais, garantidos na Constituição e nas leis.

$[\ldots]$

$\$ 2^{\circ} \mathrm{O}$ direito ao respeito consiste na inviolabilidade da integridade física, psíquica e moral, abrangendo a preservaçáo da imagem, da identidade, da autonomia, de valores, ideias e crenças, dos espaços e dos objetos pessoais.

$[\ldots]$

Art. 15.É assegurada a atenção integral à saúde do idoso, por intermédio do Sistema Único de Saúde - SUS, garantindo-lhe o acesso universal e igualitário, em conjunto articulado e contínuo das ações e serviços, para a prevençâo, promoção, proteção e recuperação da saúde, incluindo a atenção especial às doenças que afetam preferencialmente os idosos.

$[\ldots]$

$\$ 3^{\circ}$ É vedada a discriminação do idoso nos planos de saúde pela cobrança de valores diferenciados em razão da idade.

Nesse passo, a doutrina também destaca ser de notório e expressivo conhecimento que o consumidor-doente também merece a sua proteção, pois ele está mais suscetível a sofrer danos em face do abalo de sua capacidade decisória, "sendo inevitável que sua vulnerabilidade a sua vulnerabilidade natural de consumidor seja agora agravada pela morbidade humana" (MAIA, 2013).

De tal modo, a doutrina ensina que este tipo de vulnerabilidade do consumidor enfermo deve ser observada na relação médico/paciente, de forma que se exija do profissional o dever de cuidado semelhante à fragilidade biológica e psíquica agravada do doente, notadamente no que se refere ao dever de informação (BORGES, 2012; MAIA, 2013; MIRAGEM, 2007).

Cumpre ainda destacar algumas notas acerca da hipervulnerabilidade das pessoas com deficiência. Sabe-se e é de amplo conhecimento que o agravamento da vulnerabilidade deste tipo de consumidor encontra-se, principalmente, nas barreiras físicas. No que diz respeito à acessibilidade, mobilidade e informação qualificada para os deficientes visuais e auditivos, de forma que, atualmente, há a ausência de sincronia entre os serviços prestados e o grau de (in) satisfação do consumidor deficiente, uma vez que estes são oferecidos por prestadores mal treinados e, muitas vezes, sem qualificação para um atendimento adequado.

Tais circunstâncias merecem tutela especial, assim como as anteriores já mencionadas, de forma a preservar a dignidade do consumidor deficiente e garantir a sua livre participação no mercado de consumo, a fim de adquirir os produtos e serviços que lhe são oferecidos. 
Desta forma, a CF/88 foi concisa ao prever a proteção das pessoas com deficiência, estabelecendo, em seu art. 227, $\$ \$ 1^{\circ}$, II e $2^{\circ}$, o seguinte, in verbis (BRASIL 1988):

Art. 227.

[...]

$\$ 1^{\circ} \mathrm{O}$ Estado promoverá programas de assistência integral à saúde da criança, do adolescente e do jovem, admitida a participação de entidades não governamentais, mediante políticas específicas e obedecendo aos seguintes preceitos: (Redação dada Pela Emenda Constitucional no 65, de 2010).

II - Criação de programas de prevenção e atendimento especializado para as pessoas portadoras de deficiência física, sensorial ou mental, bem como de integração social do adolescente e do jovem portador de deficiência, mediante o treinamento para o trabalho e a convivência, e a facilitaçáo do acesso aos bens e serviços coletivos, com a eliminação de obstáculos arquitetônicos e de todas as formas de discriminaçãoo (Redação dada Pela Emenda Constitucional no 65, de 2010).

20 A lei disporá sobre normas de construção dos logradouros e dos edifícios de uso público e de fabricação de veículos de transporte coletivo, a fim de garantir acesso adequado às pessoas portadoras de deficiência."

De tal sorte, o CDC não prevê expressamente a proteção ao consumidor deficiente no que se refere às relaçôes de consumo (compra e venda ou prestação de serviços), mas tão somente estabelece em seus dispositivos que os serviços públicos devem ser prestados de forma adequada e eficaz, com observância na sua racionalização e melhoria contínua (BRASIL, 1990).

Por fim, outro grupo de consumidores que também merece atenção devida é o dos analfabetos. A doutrina destaca que o consumidor-analfabeto é facilmente vítima de assédio de consumo, tendo em vista a sua debilidade no que se refere ao conhecimento do conteúdo dos contratos que está assinando, podendo inclusive adquirir produtos ou serviços que não precisa ou não compreende bem o seu funcionamento (MARQUES, 2014, p. 99-146).

Importante ressaltar que apesar da referida vulnerabilidade ser temporária (como no caso de um indivíduo mais jovem, que pode aprender a ler e escrever e desenvolver as suas capacidades, independentemente da idade que tenha) leva à presunção de que ela não é capaz de entender o que está escrito no contrato ou sequer compreender as responsabilidades que assume assinando um texto contratual (DO CANTO, 2015, p. 77).

A referida vulnerabilidade, presente na realidade da população brasileira, dá ensejo às discussóes acerca do analfabetismo funcional que, de acordo com o referido autor, é de mais difícil identificaçáo no trato social (DO CANTO, 2015, p. 77).

Em suma, com base no acima exposto, nota-se que a vulnerabilidade inerente à relação de consumo soma-se à vulnerabilidade intrínseca do consumidor, seja pela idade, pelo seu estado de saúde, suas necessidades especiais, como no caso dos deficientes e até mesmo pelo seu nível de escolaridade.

Dessa forma, o consumidor resta fragilizado, tendo em vista à sua exposição face às pressóes exercidas pelo fornecedor, que tenta (e muitas vezes consegue) convencê-lo a adquirir produtos ou serviços sem que este tenha total conhecimento do contrato que está subscrevendo.

Portanto, é notório que, apesar das inovaçôes legislativas, a crítica que se faz aqui é que essas 
relações fáticas, vividas pelo consumidor no dia-dia, ainda carecem de uma autorregulamentação eficiente com viés desburocratizado, de forma a tornar acessível ao consumidor os instrumentos que este pode utilizar para a sua proteção legal no âmbito do mercado de consumo.

Nesse ínterim, passar-se-á aos comentários acerca da Lei Geral de Proteção de Dados (Lei n. 13.709/2018) (BRASIL, 2018), importante ferramenta de combate aos crimes relacionados ao direito da privacidade e proteção de dados do consumidor.

\section{Lei geral de proteçáo dos dados pessoais e CDC: Análise acerca da proteção de dados do consumidor à luz da lei n. 13.709/2018}

A Lei Geral de Proteção de Dados Pessoais - Lei n. 13.709/2018 (BRASIL, 2018), promulgada em 14 de agosto de 2018, ainda no governo Temer, que teve origem no PLC n. 53/2018, tornou-se um importante marco legal na história do ordenamento jurídico brasileiro, ao reforçar ainda mais o cumprimento das garantias e direitos fundamentais, previstos na $\mathrm{CF} / 88$, que tem como um de seus pilares a proteçáo dos Direitos Humanos (PINHEIRO, 2020, p. 15).

A referida lei, apesar de sua promulgação ter sido no segundo semestre de 2018, apresentou um dos mais longos períodos de vacatio legis que, em seu texto original, seria de 18 (dezoito) meses (BRASIL, 2018).

Contudo, após levantamentos e discussóes entre o Congresso Nacional e a Casa Civil, lançou-se a MP n. 869, de 27 de dezembro de 2018 (BRASIL, 2018), que foi posteriormente convertida na Lei n. 13.853, de 08 de julho de 2019 (BRASIL, 2019), estendendo, igualmente, o período de adaptação para 24 (vinte e quatro) meses.

De tal modo, a vigência da LGPD se iniciou no dia 18 de setembro de 2020, devido à aprovação pelo Senado da MP 959/2020 (PLV 34/2020) no final de agosto (BRASIL, 2020). O texto original da medida previa o adiamento da vigência da Lei n. 13.709/2018 para o fim do período de calamidade pública, conforme estabelecido no art. $4^{\circ}$ do PLV (SENADO, 2020).

Entretanto, em atendimento à questão de ordem e a solicitaçóes de lideranças partidárias, o presidente do Senado à época, Davi Alcolumbre, declarou a prejudicialidade desse dispositivo, que passou a ser considerado "não escrito" no projeto, transformado na Lei n. 14.058, de 2020. Alcolumbre lembrou, ainda, que em maio do mesmo ano, o Senado aprovou destaque do PDT (Partido Democrático Trabalhista) e do MDB (Movimento Democrático Brasileiro) que mantinha a vigência da LGPD para agosto de 2020 (SENADO, 2020).

A Lei n. 13.709/2018 é um marco legal que regulamenta o uso, a proteçáo e a transferência de dados pessoais no Brasil, garantindo, assim, maior controle dos cidadãos sobre suas informaçóes pessoais, exigindo consentimento explícito para coleta e uso dos dados e obriga a oferta de opçóes para o usuário visualizar, corrigir e excluir esses dados (SENADO, 2020).

Importante ressaltar que o marco regulatório foi moldado a partir da revisão e atualização de legislaçóes esparsas já existentes, a respeito da temática a fim de se adaptar à nova realidade social. Entretanto, a fim de restringir a temática que a engloba, cita-se, aqui, apenas as leis esparsas que impulsionaram o surgimento da Lei Geral de Proteção de Dados e que tem relaçáo com a proteção de dados do consumidor:

a) Lei n. 8.078/1990 - Código de Defesa do Consumidor (prevê, em seu art. 43, a criação do banco de dados de consumidores); 
b) Lei n. 9.472/1997 - Lei Geral de Telecomunicaçóes (estabelece, em seu art. 3º, os direitos do usuário do serviço de telecomunicaçōes);

c) Portaria n. 5/2002, da SDE/MJ (Secretária de Direito Econômico/Ministério da Justiça e Segurança Pública) - tornou abusivas as cláusulas de contrato de consumo que autorizam o envio de dados pessoais sem o consentimento prévio;

d) Decreto n. 6.523/2008 - Regulamenta o serviço de SAC (Serviço de Atendimento ao Consumidor) - prevê, em seu art. 11, a preservação e sigilo dos dados pessoais do consumidor, quando do atendimento;

e) Lei n. 12.414/2011 - Lei do Cadastro Positivo (prevê, em seu art. 5º, os direitos do cadastrado);

f) Lei n. 12.527/2011 - Lei de Acesso à Informação;

g) Decreto n. 7.962/2013 - Regulamenta o Comércio Eletrônico;

h) Lei n.12.965/2014 e Decreto n.8.771/2016 - Lei do Marco Civil da Internet.

Não obstante, apesar da Lei protecionista se fundamentar na legislação esparsa acima, não é possível identificar no novo conjunto normativo uma mera continuidade com a ordem anterior.

O que se nota, na realidade, é uma nova sistemática e abordagem jurídica para o problema de regulamentação do uso da informação pessoal e das garantias dos direitos do seu titular, que não poderia, de modo algum, ser implementada com base nos diplomas legais anteriores já existentes (COTS; OLIVEIRA, 2019, p. 07).

Portanto, a LGPD propóe a objetivação de regras para o tratamento dos dados pessoais. Para tanto, a referida lei traz em seu bojo conceitos fundamentais, princípios de proteção de dados pessoais, um rol taxativo de hipóteses nas quais pode ser dar o tratamento de dados pessoais, além de outros aspectos legais que se fazem necessários para elucidação e interpretação acerca da aplicação do tema (COTS; OLIVEIRA, 2019, p. 08).

Destarte, salienta-se a importância que a Lei n. 13.709/2018 tem na proteção de dados do consumidor no e-commerce, pois muitos aspectos que seu texto legal traz são aplicáveis no âmbito da relação de consumo que se dá no ambiente virtual, conforme será visto a seguir.

\subsection{Tratamento de dados pessoais}

O tratamento de dados pessoais, nos ensinamentos de Oliveira, deve ser feito mediante o enquadramento em uma das bases legais do art. 7º da Lei n. 13.709/2018 (COTS; OLIVEIRA, 2019, p 83).

Contudo, por se tratar de um rol exaustivo, serão abordadas apenas as bases legais que detém relação com a proteção de dados do consumidor.

Assim, o dispositivo em comento prevê que o tratamento de dados poderá ser realizado nas seguintes hipóteses:

a) Mediante o fornecimento de consentimento do titular;

b) Quando necessário para a execução de contrato ou de procedimentos preliminares relacionados a contrato do qual seja parte o titular, a pedido do titular dos dados; e 
c) Para a proteção do crédito, inclusive quanto ao disposto na legislação pertinente.

No que se refere à primeira hipótese, salienta-se que o consentimento do titular de dados é de fundamental importância para que se garanta a qualidade e segurança no tratamento de seus dados.

Dessa forma, garantir que as pessoas/usuários tenham ciência de que devem consentir o uso de dados, assim como tenham direito de saber a finalidade da coleta e acesso ao seu conteúdo em qualquer momento, é primordial para assegurar a liberdade e privacidade (PINHEIRO, 2020, p. 85).

Já a segunda hipótese remete à teoria geral dos contratos, já abordado em tópico anterior deste trabalho.

Não é demais relembrar, de forma sintética, que o contrato é o acordo de duas ou mais vontades [...] destinado a estabelecer uma regulamentação de interesses entre as partes, com o escopo de adquirir, modificar ou extinguir relaçôes jurídicas de natureza patrimonial (DINIZ, 2008).

Neste sentido, Oliveira destaca que a fase antecedente da contratação geralmente envolve a proposta ou o contrato preliminar, sendo que ambas dependem do tratamento de dados pessoais para a adequada identificação das partes ou de seus representantes (COTS; OLIVEIRA, 2019, p. 86). Portanto, ao redigir a hipótese em comento, o legislador optou por não permitir o tratamento de dados pessoais na fase de formação dos contratos, mas tão somente em sua execução, ou seja, antes disso, o tratamento só poderá ser realizado mediante o consentimento legal do titular (COTS; OLIVEIRA, 2019, p. 86).

Quanto à hipótese de proteção de crédito, salienta-se que esta hipótese já foi aborda em tópico anterior, quando se explicou acerca do banco de dados e cadastros de consumo.

Não obstante, importante destacar alguns pontos relevantes acerca do crédito financeiro, uma vez que se trata de uma ferramenta trivial para a movimentação da economia (COTS; OLIVEIRA, 2019, p. 90). Pois bem, o crédito financeiro viabiliza tanto o desenvolvimento pessoal quanto o empresarial, injetando importantes recursos no mercado nacional e impactando beneficamente seus personagens como um todo (COTS; OLIVEIRA, 2019, p. 90). Contudo, a referida atividade oferece riscos, podendo ser concretizado pela inadimplência, degradaçáo de crédito ou, ainda, pela degradação de garantias (COTS; OLIVEIRA, 2019, p. 90).

Igualmente, foram criados mecanismos dos quais o mercado tenta se precaver dos riscos desconhecidos ou, ainda, mapear a abrangência de riscos conhecidos, sendo o principal: as entidades de proteção de crédito (COTS; OLIVEIRA, 2019, p. 90). Nesse contexto surgiu a Lei do Cadastro Positivo (Lei n. 14.414/2011), prevendo a criaçáo de banco de dados de adimplentes, fazendo com que o risco pelo oferecimento de crédito a si fosse menor do que para pessoas que não constavam em tal cadastro (COTS; OLIVEIRA, 2019, p. 90).

Salienta-se que a referida lei foi uma das precursoras à criação da lei protecionista, uma vez que muito do que consta na primeira, serviu de base normativa para a segunda.

\subsection{Adoção de boas práticas a fim de se resguardar a proteção dos dados do consumidor}

Por fim, comentar-se-á, aqui, acerca da segurança e boas práticas para que se torne possível 
a qualidade na proteção e tratamento de dados do consumidor.

A Lei n. 13.709/2018 prevê, em seu art. 46, que os agentes de tratamento devem adotar medidas de segurança, técnicas e administrativas aptas a proteger os dados pessoais de (BORELLI et al., 2019, p. 266):

a) Acessos não autorizados;

b) Situaçôes acidentais (nos casos de culpa: negligência, imprudência ou imperícia); ou

c) Ilícitas (cometidas com dolo).

Neste sentido, a respeito da segurança da informação, a norma ISO/IEC 17799:2005 a define como sendo: "a proteção da informação de vários tipos de ameaças para garantir a continuidade do negócio, minimizando os riscos, maximizando o retorno sobre os investimentos e as oportunidades de negócio” (BRASIL, 2005).

De tal modo, Oliveira ressalta que as medidas de segurança são de elevada importância, porém, não geram seus efeitos sendo aplicadas de forma isolada, dependendo, para isso, de medida técnicas e administrativas (COTS; OLIVEIRA, 2019, p. 191).

Salienta-se, ainda, a comunicação em caso de incidentes, prevista no art. 48 da lei protecionista. $\mathrm{O}$ referido ato guarda muita semelhança com o denominado recall, previsto no art. 10, do CDC (BRASIL, 1990):

Art. 10. O fornecedor não poderá colocar no mercado de consumo produto ou serviço que sabe ou deveria saber apresentar alto grau de nocividade ou periculosidade à saúde ou segurança.

$\S 1^{\circ} \mathrm{O}$ fornecedor de produtos e serviços que, posteriormente à sua introdução no mercado de consumo, tiver conhecimento da periculosidade que apresentem, deverá comunicar o fato imediatamente às autoridades competentes e aos consumidores, mediante anúncios publicitários.

Não obstante, a comunicação prevista na Lei n. 13.709/2018 deve observar algumas formalidades em seu conteúdo, contendo o seguinte: a) descrição da natureza dos dados pessoais afetados; b) informaçôes sobre os titulares envolvidos; c) indicação das medidas técnicas e de segurança utilizadas para a proteção dos dados, observados os segredos comercial e industrial; d) riscos relacionados ao incidente; e) motivos da demora, no caso de a comunicação não ter sido imediata; e f) as medidas que foram ou que serão adotadas para reverter ou mitigar os efeitos do prejuízo.

No que se refere ao encaminhamento da comunicação, a lei n. 13.709/2018 prevê que deve ser feito pelo controlador. Entretanto, se houver incidente no âmbito do operador, este deverá comunicar o controlador imediatamente, a fim de que ele cumpra com sua obrigação legal (COTS; OLIVEIRA, 2019, p. 199).

A lei protecionista estabeleceu, também, a possibilidade de controladores e operadores, sozinhos ou coletivamente, criarem boas práticas corporativas para o tratamento de dados pessoais (COTS; OLIVEIRA, 2019, p. 201).

Desta forma, haverá a possibilidade de ser implementado o que a LGPD denominou: "programa de governança em privacidade", semelhante a já conhecida política de segurança da informação, porém focado no cumprimento na nova lei. Assim, demonstrando o comprometimento do agente de tratamento em cumprir e fazer cumprir a lei em relação aos seus 
contratados (COTS; OLIVEIRA, 2019, p. 203).

Portanto, de acordo com a doutrina, a disposição no art. 50 pactua com as atuais políticas empresariais de governança e compliance, que visam, de modo geral, a realizar uma adequada gestão de riscos, por meio de boas práticas, atendimento da legislação e regulamentos incidentes sobre o negócio e a criação de controles internos (COTS; OLIVEIRA, 2019, p. 203).

Logo, nota-se uma forte tendência da LGPD no âmbito do tratamento de dados pessoais, notadamente nas relaçóes de consumo virtuais. No sentido de que os mesmos sejam gestados pelas empresas de forma a se assegurar prioritariamente a integridade, segurança e transparência acerca das informaçôes que são levadas ao consumidor, proporcionando, via de consequência, um ambiente adequado para a manutenção de seus dados e informaçôes cadastrais.

\section{Consideraçôes finais}

Após uma abordagem analítica acerca do conceito de consumidor, destacando-se aí o surgimento da hipervulnerabilidade, característica das relaçôes de consumo virtuais, notadamente no que se refere ao tratamento de dados pessoais do titular, nota-se o quáo relevante é a referida lei dentro da relação de consumo virtual.

Demonstrou-se nesta pesquisa que o consumidor, quando inserido no ambiente virtual, torna-se hipervulnerável, uma vez que o mesmo fica impedido de reconhecer fisicamente o fornecedor de serviços ou produtos, bem como há a impossibilidade de se verificar se o serviço/ produto que está sendo ofertado condiz com o que o consumidor pretende obter.

Verificou-se, ainda, que o fornecedor, devido à posição em que se encontra na relação de consumo, detém certas prerrogativas que fazem com que o seu negócio evolua de forma exponencial, através da aplicação de banco de dados e cadastro de consumo previamente coletados e tratados.

Tal fato se concretiza quando o consumidor acessa um site de compras para consultar serviços/produtos e, com base nisso, torna-se possível criar um perfil de consumo do indivíduo com base nos produtos/serviços que este acessa.

Insta frisar que o comércio eletrônico leva ao fornecedor uma série de responsabilidades que devem ser cumpridas, de modo que esta forneça ao consumidor um serviço/produto de forma transparente, segura, e respeitando a integridade da informação, a fim de que esta cumpra sua real finalidade, qual seja, a de levar ao contratante as respostas que este necessita.

Além disso, esta pesquisa se dedicou a investigar a aplicabilidade que a lei protecionista estabelece para os demais campos do Direito. Desta forma, a lei protecionista cria uma relaçáo interdisciplinar com o campo do Direito do Consumidor, quando se levanta o debate acerca do banco de dados e cadastros de consumo, dois institutos que merecem destaque quando se discute acerca da segurança na manutenção dos dados do consumidor ali inseridos. Portanto, o que se extrai desta pesquisa é o nível da proporção que a lei protecionista pretendeu abarcar com a sua vigência.

Trata-se de uma lei multidisciplinar, pois não apenas trouxe para o Ordenamento Jurídico brasileiro institutos seguradores da proteção de dados pessoais (com, por exemplo, os princípios que a Lei Geral de Proteção de Dados elenca), como também, previu uma política de segurança 
de informação com base no estabelecimento da relação de consumo, permitindo uma maior eficiência no tratamento de dados pessoais.

Muito do que se esperava na legislação até então existente, foi concretizada na LGPD, a partir do momento em que se tornou possível prever os benefícios e riscos na gestão de dados pessoais de um determinado indivíduo, e as consequências de seu tratamento em desconformidade com a lei. Assim, surgiram os agentes de tratamento - controlador e operador - personagens indispensáveis para a concretização do procedimento de gestão de dados pessoais.

Não obstante, importante ressaltar que a lei muito tem a melhorar, notadamente, no que se refere às disposiçóes acerca da autoridade nacional, outra figura que acaba se tornando trivial para o funcionamento do arcabouço normativo.

Logo, a Lei n. 13.709/2018 se trata essencialmente de uma ferramenta de combate às ilegalidades no tratamento de dados pessoais, visa a estabelecer uma zona de segurança para quem consente o uso de seus dados, principalmente ao consumidor que utiliza a internet para realizar compras e contratar serviços. Porém, o que se nota, na atualidade, é a ausência de políticas públicas para que se concretize o a finalidade precípua da referida lei dentro do e-commerce, que é estabelecer uma zona de segurança para o consumidor no tocante à guarda e manutençáo de seus dados pessoais.

\section{Referências}

BENJAMIN, Antônio Herman de Vasconcellos e. Código brasileiro de defesa do consumidor: comentado pelos autores do anteprojeto. Rio de Janeiro: Forense, 2011.

BLUM, Rita Peixoto Ferreira. O direito à privacidade e à proteção de dados do consumidor. São Paulo: Almedina, 2018.

BORELLI, Alessandra et al. LGDP: Lei Geral de Proteção de Dados Comentada. 2a ed. São Paulo: Thomson Reuters Brasil, 2019.

BORGES, Gustavo Silveira. Diálogo das fontes e responsabilidade civil médica: (re)leitura da relação médico-paciente a partir da interdisciplinaridade. Revista de Direito do Consumidor: RT, São Paulo, v. 21, n. 84, p. 13-44, out./dez/ 2012.

BRASIL. Código de Defesa do Consumidor. Disponível em: <http://www.planalto.gov.br/ ccivil_03/leis/l8078compilado.htm>. Acesso em: 22 de junho de 2021.

BRASIL. Constituição Federal de 1988. Disponível em: <http://www.planalto.gov.br/ccivil_03/ constituicao/constituicaocompilado.htm>. Acesso em: 22 de junho de 2021.

BRASIL. Lei n. 10.741/2003 - Dispóes sobre o Estatuto do Idoso e dá outras providências. Disponível em: <http://www.planalto.gov.br/ccivil_03/leis/2003/L10.741compilado.htm>. Acesso em: 30 de junho de 2021.

BRASIL. Lei n. 13.709/2018 - Dispóe sobre a proteção de dados pessoais e altera a Lei no 12.965, de 23 de abril de 2014 (Marco Civil da Internet). Disponível em <https://www2.camara.leg.br/ legin/fed/lei/2018/lei-13709-14-agosto-2018-787077-publicacaooriginal-156212-pl.html>. Acesso em 15 mar 2021. 
BRASIL. Lei n. 13.853/2019 - Altera a Lei no 13.709, de 14 de agosto de 2018, para dispor sobre a proteção de dados pessoais e para criar a Autoridade Nacional de Proteção de Dados; e dá outras providências. Disponível em: <http:/www.planalto.gov.br/ccivil_03/_ato2019-2022/2019/lei/ 113853.htm>. Acesso em: 26 de junho de 2021.

BRASIL. MP 959/2020. Disponível em: <http:/www.planalto.gov.br/ccivil_03/_ato20192022/2020/mpv/mpv959.htm>. Acesso em: 24 de junho de 2021.

BRASIL. Norma ISO/IEC 17799:200. 2005. Disponível em: <https://www.abntcatalogo.com. br/norma.aspx?ID=60452>. Acesso em: 26 de junho de 2021.

BRASIL. PLV 34/2020. Disponível em: <https://www.camara.leg.br/propostaslegislativas/2260915>. Acesso em: 24 de junho de 2021.

COTS; Márcio; OLIVEIRA, Ricardo. Lei geral de proteção de dados pessoais comentada. $3^{\mathrm{a}}$ Edição. São Paulo: Thomson Reuters Brasil, 2019.

DINIZ, Maria Helena. Curso de Direito Civil Brasileiro. 25ª ed. São Paulo: Saraiva, 2008.

DO CANTO, Rodrigo Eidelvein. A vulnerabilidade dos consumidores no comércio eletrônico: reconstrução da confiança na atualização do Código de Defesa do Consumidor. São Paulo: Revista do Tribunais, 2015.

GARCIA, Leonardo. Código de Defesa do Consumidor - comentado artigo por artigo. São Paulo: Juspodvim, 2017.

JONH F. KENNEDY PRESIDENTIAL LIBRARY E MUSEUM.

Specialmessagetocongressonprotectingconsumerinterest, 1962. Disponível em: <http://www. jfklibrary.org/Asset-Viewer/Archives/JFKPOF-037-028.aspx>. Acesso em: 22 de junho de 2021.

MAIA, Maurilio Casas. O paciente hipervulnerável e o princípio da confiança informada na relação médica de consumo. Revista de Direito do Consumidor: RT, São Paulo, v. 22, n. 86, p. 203-232, mar./abr. 2013.

MARQUES, Cláudia Lima. Comentários ao Código de Defesa do Consumidor. São Paulo: Revista dos Tribunais, 2003.

MARQUES, Cláudia Lima. Confiança no comércio eletrônico e a proteção do consumidor: um estudo dos negócios jurídicos de consumo no comércio eletrônico. São Paulo, Revista dos Tribunais, 2004.

MARQUES, Cláudia Lima. Contratos no código de defesa do consumidor: o novo regime das relaçôes contratuais. 6ª ed. São Paulo: RT, 2011.

MARQUES, Cláudia Lima. Estudo sobre a vulnerabilidade dos analfabetos na sociedade de consumo: o caso do crédito consignado a consumidores analfabetos. Revista de Direito do Consumidor, vol. 23, n. 95, p. 99-146, São Paulo: RT, set.-out., 2014.

MARQUES, Cláudia Lima; BENJAMIN, Antônio Herman V; MIRAGEM, Bruno. Comentários ao Código de Defesa do Consumidor. 3a ed. São Paulo: RT, 2010.

MARQUES, Cláudia Lima; BENJAMIN, Antônio Herman V; MIRAGEM, 
Bruno. Comentários ao Código de Defesa do Consumidor. 4a ed. São Paulo: RT, 2013.

MARQUES, Cláudia Lima; MIRAGEM, Bruno Nuvens Barbosa. O novo direito privado e a proteção dos vulneráveis. São Paul: RT, 2012.

MIRAGEM, Bruno Nuvens Barbosa. Responsabilidade civil médica no direito brasileiro. Revista de Direito do Consumidor: RT, São Paulo, v. 16, n. 63, p. 52-91, jul./set/ 2007.

MIRAGEM, Bruno Nuvens Barbosa. Curso de Direito do Consumidor. São Paulo: Revistas do Tribunais, 2012.

MORAES, Paulo Valério Dal Pai. Código de Defesa do Consumidor: o princípio da vulnerabilidade no contrato, na publicidade, nas demais práticas comerciais: interpretação sistemática do direito. $3^{\mathrm{a}}$ ed. Porto Alegre: Livraria do advogado, 2009.

NERY JÚNIOR, Nelson. Código Brasileiro de Defesa do Consumidor Comentado Pelos Autores do Anteprojeto. 6a ed. Rio de Janeiro: Forense Universitária, 2000, p.430.

NISHIYAMA, Adolfo Mamoru. $A$ proteção dos consumidores hipervulneráveis: os portadores de deficiência, os idosos, as crianças e os adolescentes. Revista de Direito do Consumidor, São Paulo: RT, v. 19, n. 76, p. 13-45, out./dez. 2010.

PINHEIRO, Patricia Peck. Proteção de dados pessoas: comentários à Lei n. 13.709/2018 (LGPD). 2 ed. São Paulo: Saraiva Jur, 2020.

SENADO. Lei Geral de Proteção de Dados Pessoais entra em vigor. Site do Senado Federal, 2020. Disponível em: <https://www12.senado.leg.br/noticias/materias/2020/09/18/lei-geral-deprotecao-de-dados-entra-em-vigor>. Acesso em: 24 de junho de 2021.

TARTUCE, Flávio. Manual de direito do consumidor: direito material e direito processual. $5^{\text {a }}$ ed. São Paulo: Método, 2016.

TARTUCE, Flávio. Manual de direito civil: volume único. Rio de Janeiro: Forense; São Paulo: Método, 2020. 